\title{
BMJ Open Differences in research funding for women scientists: a systematic comparison of UK investments in global infectious disease research during 1997-2010
}

\author{
Michael G Head, ${ }^{1}$ Joseph R Fitchett, ${ }^{2}$ Mary K Cooke, ${ }^{1}$ Fatima B Wurie, ${ }^{1}$ Rifat Atun ${ }^{3,4}$
}

To cite: Head MG, Fitchett JR, Cooke MK, et al. Differences in research funding for women scientists: a systematic comparison of UK investments in global infectious disease research during 1997-2010. BMJ Open 2013;3:e003362. doi:10.1136/bmjopen-2013003362

- Prepublication history and additional material for this paper is available online. To view these files please visit the journal online (http://dx.doi.org/10.1136/ bmjopen-2013-003362).

Received 7 June 2013 Revised 12 October 2013 Accepted 15 October 2013

CrossMark

For numbered affiliations see end of article.

Correspondence to Michael G Head;

m.head@ucl.ac.uk

\section{ABSTRACT}

Objectives: There has not previously been a systematic comparison of awards for research funding in infectious diseases by sex. We investigated funding awards to UK institutions for all infectious disease research from 1997 to 2010, across disease categories and along the research and development continuum.

Design: Systematic comparison.

Methods: Data were obtained from several sources for awards from the period 1997 to 2010 and each study assigned to-disease categories; type of science (preclinical, phases I-III trials, product development, implementation research); categories of funding organisation. Fold differences and statistical analysis were used to compare total investment, study numbers, mean grant and median grant between men and women.

Results: 6052 studies were included in the final analysis, comprising 4357 grants (72\%) awarded to men and 1695 grants (28\%) awarded to women, totalling $£ 2.274$ billion. Of this, men received £1.786 billion $(78.5 \%)$ and women $£ 488$ million $(21.5 \%)$. The median value of award was greater for men ( $£ 179389$; IQR $£ 59$ 146-£371 977) than women ( 1125 556; IQR $£ 30$ 982-£261 834). Awards were greater for male principal investigators (PIs) across all infectious disease systems, excepting neurological infections and sexually transmitted infections. The proportion of total funding awarded to women ranged from $14.3 \%$ in 1998 to $26.8 \%$ in 2009 (mean 21.4\%), and was lowest for preclinical research at $18.2 \%$ ( $£ 285.5$ million of $£ 1.573$ billion) and highest for operational research at $30.9 \%$ (£151.4 million of $£ 489.7$ million).

Conclusions: There are consistent differences in funding received by men and women PIs: women have fewer funded studies and receive less funding in absolute and in relative terms; the median funding awarded to women is lower across most infectious disease areas, by funder, and type of science. These differences remain broadly unchanged over the 14-year study period.

\section{INTRODUCTION}

Women are under-represented in biomedical science, yet few studies have systematically
Strengths and limitations of this study

- This is the first study to present detailed data and rigorously quantify funding differences between men and women researchers in infectious disease research in the UK.

- Our results provides new and additional evidence on differences on funding for men and women researchers highlighted in earlier studies and provides a case for new research to explain the source of these differences, especially given the government commitments to increase the number of women in science.

- We were unable to assess the success and failure rates by gender and thus cannot comment on the extent of inequalities or bias. As we could not feasibly access data on the academic ranking of principal investigators, we were hence unable to adjust for levels of seniority across both genders. A follow-up study incorporating these data would allow for more meaningful conclusions to be drawn about the nature of any possible disparities.

explored the extent and reasons for the observed differences between men and women scientists. Women comprise $50 \%$ of the European Union (EU) student population and $45 \%$ of doctoral students, but only one-third of career researchers are womena figure that is lower for senior positions. ${ }^{1}$

In 2001, a Wellcome Trust survey concluded that although women were as successful as men in securing funding for biomedical research, they were less likely to apply for grant funds because of their status in scientific institutions and the level of support they received. ${ }^{2}$ An analysis of Wellcome Trust awards in 20002008 revealed a significant gender difference in the amount of funding awarded, even after adjusting for the seniority of the principal investigator (PI), concluding "the most likely explanation for the difference in amounts awarded to women and men is that women are 
systematically less ambitious in the amounts of funding requested in their grant applications." ${ }^{3}$ In 2011, around $44 \%$ of academics in UK universities were women, yet only $39 \%$ of senior lecturers and $19 \%$ of professors were women. ${ }^{4}$ Furthermore, a number of studies from the USA have shown that women in science are disadvantaged compared to men. ${ }^{5-7}$

The low numbers of women in science and the reasons for this anomaly are a matter of concern for scientists and policy-makers. Although the UK Medical Research Council (MRC) has a gender equality scheme, which briefly states that gender equality is reflected in agreements with research organisations receiving MRC funding, it is not clear how the scheme is implemented.8

While several initiatives have aimed to increase the numbers of women involved in science, there are no affirmative actions or binding policies in the UK or Europe to definitively ensure that women are better represented in science. Indeed, some initiatives aimed at increasing women in science have been criticised. For example, in 2012, the European Commission campaign targeting 13-year-old to 18-year-old secondary school students $^{9}$ was rebuked and described as an insult to women in science, ${ }^{10}{ }^{11}$ with the offending video clip removed from the EU campaign website. The effects of campaigns aimed at raising the profile of women in science ${ }^{1213}$ have not been assessed.

We have previously undertaken a systematic analysis of research funding awarded to UK institutions for all infectious disease research for the 14-year period from 1997 to $2010 .{ }^{14}$ Here, we use the dataset gathered for this earlier study to examine trends over time, the distribution of funding awarded to men and women PIs across specific infections, funder categories and along the research and development (R\&D) continuum, extending from preclinical to clinical and operational research.

\section{METHODS}

We obtained data from several sources for infectious disease research studies where funding was awarded between 1997 and 2010. The methods for the original study are elaborated in detail elsewhere ${ }^{14}$ and summarised here. We identified 325922 studies for screening that covered all areas of disease from several funders, and filtered these to identify funding for infectious diseases where the lead institution was in the UK in the period and the year of award 1997-2010. We obtained data from publicly available sources and directly from the funders. We did not include private sector funding in the analysis, as pharmaceutical sector data were not publicly available. Figure 1 shows the sources of data and the numbers of studies included and excluded at each stage of screening to reach the final set of studies for detailed analysis.

Data collection and cleaning took place alongside routine duties between 2006 and 2011, primarily by
MGH and assisted by JRF, MKC and FBW. Funding records could feasibly be obtained going back to 1997, hence the decision to cover awards during 1997-2010. We assigned each study to primary disease categories, and within each category we documented topic-specific subsections, including specific pathogen or disease. We allocated studies to one of four categories along the R\&D continuum: preclinical; phases I, II or III; product development; and operational research, and to 1 of the 26 categories for funding organisations.

Where the PI was named, we assigned them to men or women categories. The studies where only an initial was available for the forename were assigned as 'unclear' if we were unable to establish the PI's gender from a review of the literature, institutional websites or publicly available publications and documents.

Reference to sexually transmitted infections excludes HIV. Neglected tropical diseases were categorised according to the classification used by the WHO (http://www. who.int/neglected_diseases/diseases/en). Antimicrobial resistance includes antibacterial, antiviral, antifungal and antiparasitic studies.

We converted grants awarded in a currency other than pounds sterling to UK pounds using the mean exchange rate in the year of the award. We adjusted grant funding amounts for inflation and reported in 2010 UK pounds.

As well as excluding studies not immediately relevant to infection, we excluded unfunded studies, veterinary infectious disease research studies (unless there was a zoonotic component), those exploring the use of viral vectors to investigate non-communicable diseases, grants for symposia or meetings or studies with UK contributions (eg, as a collaborator), but the funding was awarded to a non-UK institution.

We used Microsoft Excel versions 2000 and 2007 to categorise studies. Where needed, data were exported into Microsoft Access (versions 2000 and 2007) and specific keyword queries used to select precise sections of the data for analysis. We used Stata (V.11.0) for statistical analysis and to generate figures.

We used fold differences to compare total investment, number of studies, mean grant and median grant between men and women according to disease system, specific infection and funding organisation.

We used the non-parametric Mann-Whitney rank-sum test to assess the distribution of funding by gender. The non-parametric K-sample test on equality of medians was applied to compare the median funding by gender, and reported as a $\chi^{2}$ statistic without Yates' correction for continuity. The non-parametric Wilcoxon signed-rank test was applied when comparing matched data, such as time trends by gender. The significance for all tests was defined at the 5\% level (twosided $\mathrm{p}=0.05$ ).

We present differences between gender and do not attempt to investigate or imply bias or inequalities as we could not access data on unsuccessful grant applications. 


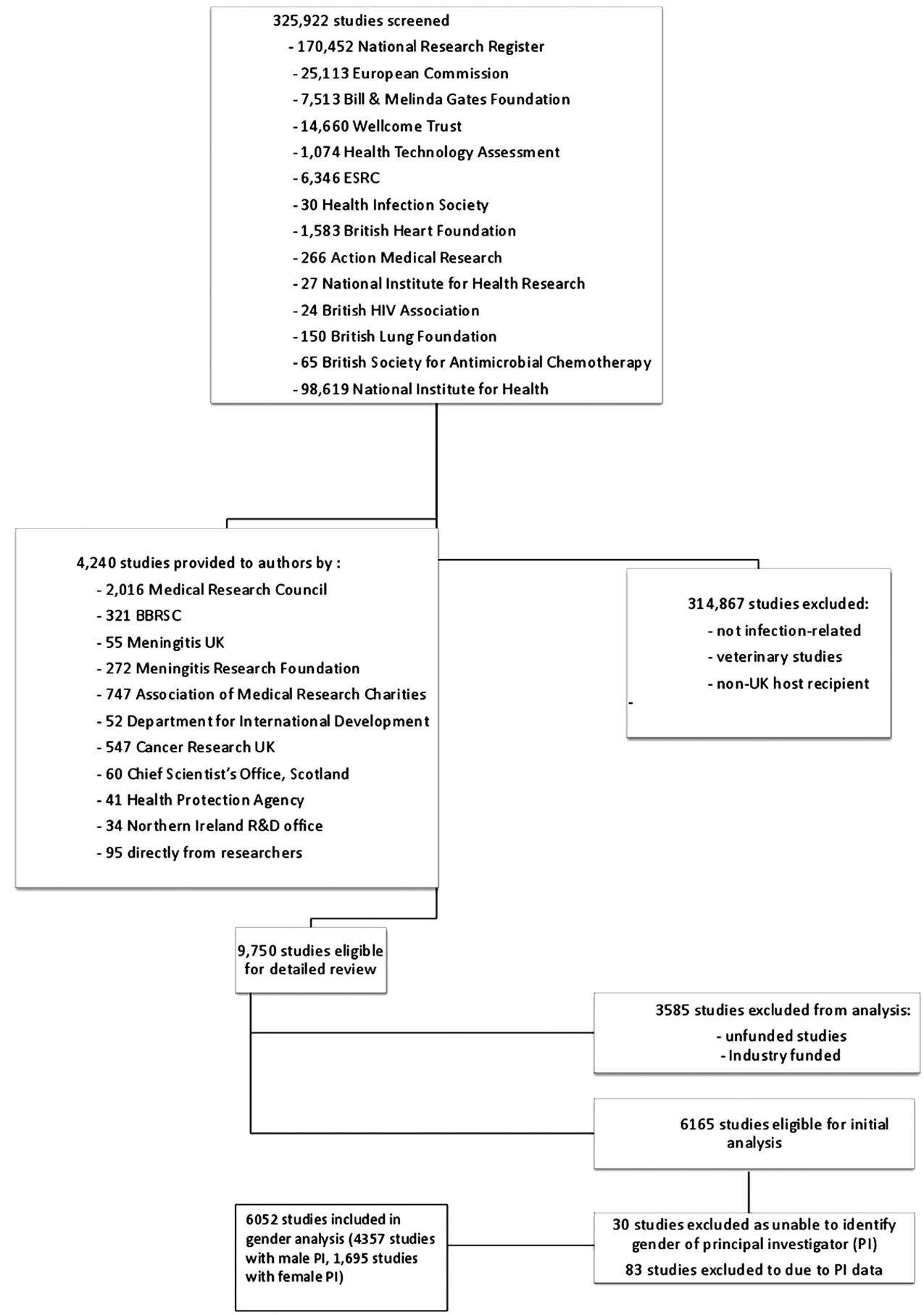

Figure 1 Methodology flow chart for filtering studies first by infectious disease and then by gender. BBSRC, Biotechnology and Biological Sciences Research Council; ESRC, Economic and Social Research Council; PI, principal investigator; R\&D, research and development.

\section{RESULTS}

We identified 6165 studies from the 325922 studies screened that were suitable for inclusion in our analysis. Of these, we were unable to ascertain the gender of the PI for 30 studies $(0.5 \%)$. We excluded 83 studies (1.3\%) that did not specify the PI's name or gender-these were funded by the Bill \& Melinda Gates Foundation (Gates Foundation; 38 studies; $0.6 \%$ ) and the UK Department for International Development (DFID; 22 studies; $0.4 \%$ ), accounting for $£ 321.2$ million (12.3\% of the total). We included 6052 studies in the final analysis, comprising 4357 grants (72\%) awarded to men and 1695 grants $(28 \%)$ awarded to women, totalling $£ 2.274$ billion, of which $£ 1.786$ billion $(78.5 \%)$ were awarded to men and $£ 488$ million $(21.5 \%)$ to women.

The median value of grant funding was greater for men ( $£ 179$ 389; IQR £59 146-£371 977) than for women (£125 556; IQR £30 982-£261 834). Similarly, the mean 
value of the grant funding was greater for men (£409 910; SD £840 087) than for women ( 2880011 ; SD $£ 704$ 474). Figure 2 shows the distribution of the total investments and median funding awarded to PIs by gender over time.

\section{Infectious disease system}

Table 1A (see web appendix 1) shows the total investment, total numbers of studies, mean grant funding, median grant funding and fold differences in funding according to nine disease systems and by gender of PI. We identified no infectious disease system where women led the majority of research efforts or were awarded the majority of funding. Median funding awards were greater for male PIs across all infectious disease systems, with the exception of neurological infections and sexually transmitted infections.

The greatest levels of funding awarded to men and to women were for research into respiratory infections and HIV. Men received a total of £312.1 million for research into respiratory infections compared with $£ 84.4$ million for women-a 3.70-fold difference-and a total of $£ 290.8$ million for HIV research compared with £79.7 million for women-a 3.65-fold difference.

The largest difference between total funding for men and for women was with gastrointestinal infections (5.65-fold difference) where women received only $15 \%$ of the total investment (£37 million) and spearheaded $18.9 \%$ (149) of the studies and neurological infections (4.22-fold difference). The smallest difference between
Figure 2 (A) Total investment over time awarded to male and female principal investigators. (B) Median investment over time awarded to male and female principal investigators.
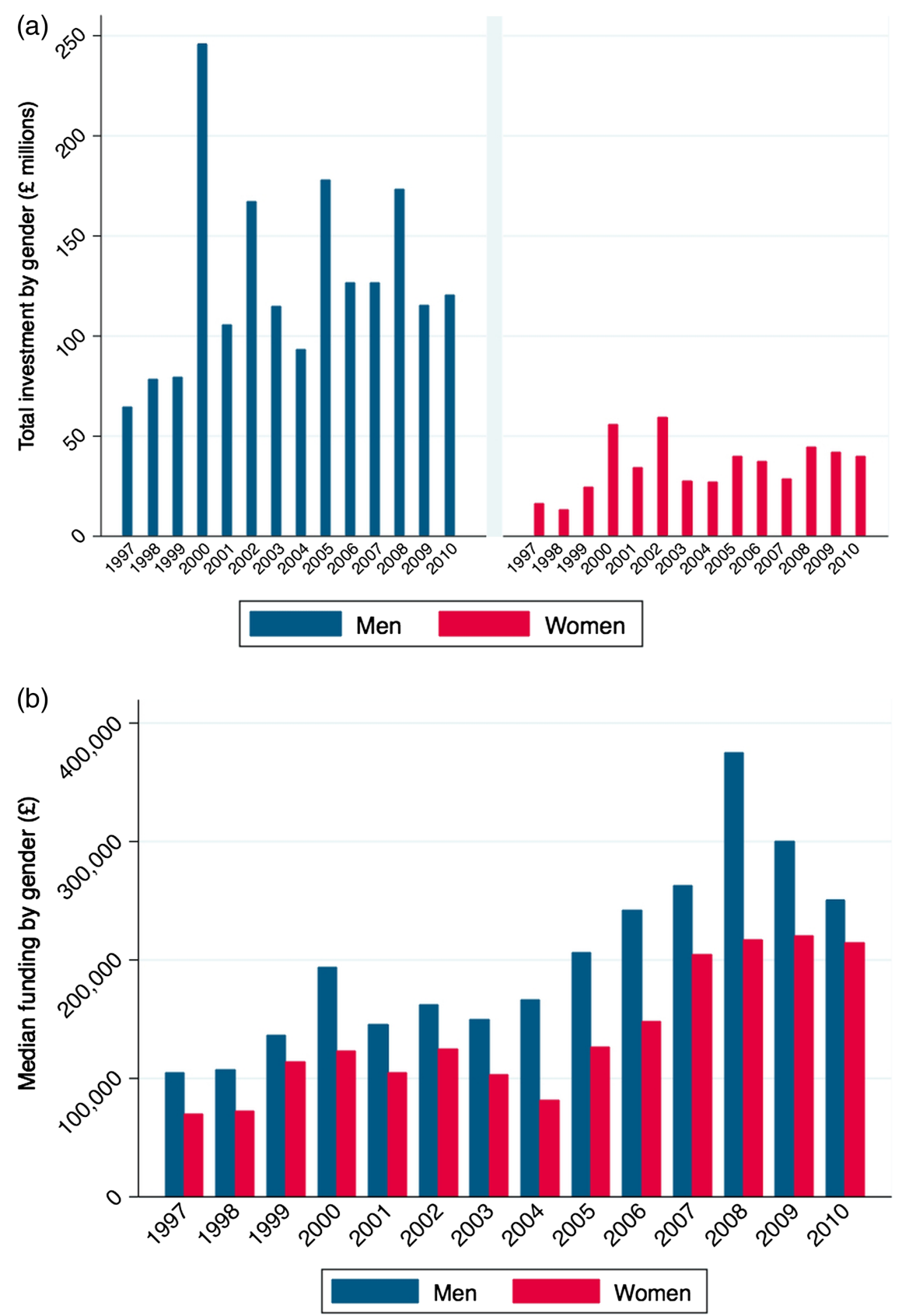
total funding for men and for women was in research into sexually transmitted infections (1.90-fold difference), where women received $35 \%$ ( $\$ 45.4$ million) of the total funding and led 49\% (182) of the studies.

The mean funding for grants was significantly greater for men ( $£ 409910$, SD $£ 840087$ ) than for women (£288 011, SD £704 474). The differences in median funding were statistically significant $(p>0.01)$ for gastrointestinal infections (men £328 021; SD £458 720) (women $£ 248615$, SD $£ 433176$ ), for haematological infections (men £417 889; SD £914 626) (women $£ 306$ 126; SD £819 910) and for HIV (men £649 216; SD $£ 1550$ 920) (women £278 505; SD £545 657).

The median funding for grants showed a similar pattern, with a significantly greater grant funding for men (£179 389; IQR £59 146-£371 977) than women (£125 556; IQR £30 983-£261 835). Differences in median funding were statistically significant $(\mathrm{p}>0.05)$ for gastrointestinal infections (men £208 369; IQR £78 852-357 771) (women $£ 155$ 066; IQR £43 637-£305 928), for hepatic infections (men £118 638; IQR £41 342-£269 629) (women £68 620; IQR £26 720-£221 952) and for HIV (men £163 462; IQR $£ 39$ 153-£511 800) (women £114 272; IQR £29 880$£ 305$ 339).

\section{Specific infections}

Table 1B (see web appendix 1) shows total investment, total numbers of studies, mean grant funding, median grant funding and fold differences in funding according to specific infection by gender.

Men received significantly higher levels of total research funding, spearheaded greater numbers of studies and were awarded greater median and mean funding for grants for malaria $(p=0.01)$, HIV $(p=0.01)$ and influenza $(\mathrm{p}=0.04)$.

Major differences between total funding for men and for women were observed for research into candida (47.75-fold difference), rotavirus (33.65-fold difference), Campylobacter (24.33-fold difference) and norovirus (23.33-fold difference). Smallest differences between total funding for men and women were observed for research into dengue (1.07-fold difference) and leishmaniasis (1.55-fold difference). Women received greater total funding than men for research into leprosy (0.09-fold difference), diphtheria (0.18-fold difference), chlamydia (0.36-fold difference), syphilis (0.37-fold difference) and varicella zoster (0.54-fold difference).

Differences in mean grant funding were statistically significant ( $>0.05$ ) for malaria research (men $£ 590$ 422; SD $£ 1324$ 909) (women £318 054; SD £726 872), for influenza (men £616 643; SD £881 493) (women £387 186; SD $£ 489$ 997), for respiratory syncytial virus (men $£ 485$ 283; SD £539 396) (women £187 931; SD £268 412) and for HIV (men £649 216; SD £1 550 920) (women £278 505; SD $£ 545657)$.

Differences in median grant funding were statistically significant $(p>0.05)$ for malaria research (men £209 646; IQR £63 826-£529 610) (women £143 358;
IQR £42 754-£314 524), for hepatitis C (men £124 797; IQR £42 475-£289 293) (women £67 265; IQR £29 880$£ 233467$ ), for influenza (men £348 730; IQR £213 601$£ 668$ 561) (women £200 787; IQR £124 210-£398 191), for herpes simplex virus (men $£ 119$ 295; IQR $£ 40009$ $£ 446$ 395) (women £309 610; IQR £147 885-£439 305) and for HIV (men £163 462; IQR £39 153-£511 800) (women £114 272; IQR £29 880-£305 339).

Figure 3 shows the proportion of total funding awarded to PIs by gender over time and a breakdown of investment by research pipeline. The proportion of the total funding awarded to women ranged from $14.3 \%$ (in 1998) to $26.8 \%$ (in 2009), with a mean proportion of $21.4 \%$ for the period studied. The proportion of funding was lowest for preclinical research at $18.2 \%$ ( $£ 285.5$ million of $£ 1.573$ billion total) and highest for operational research at $30.9 \%$ (£151.4 million of $£ 489.7$ million). The funding for clinical (phases I-III) research was $29.9 \%$ (£25.5 of £85.2) and for product development it amounted to $20.4 \%$ (£25.8 million of £126.6 million).

\section{Funding organisation}

Table 2 (see web appendix 2) shows in detail the total investment, total numbers of studies, mean grant funding, median grant funding and fold differences in funding according to funding organisation and by gender.

Public funding organisations invested a total of $£ 1.025$ billion in research led by men $(78.6 \%)$ and £279.8 in research led by women (21.4\%). The greatest levels of funding awarded to men and to women were by the Wellcome Trust and the UK MRC. Major differences between funding awarded to men and to women PIs were by the Biotechnology and Biological Sciences Research Council (BBSRC), with a 6.12-fold difference. Smallest differences between funding awarded to men and to women were by the UK Government funding streams such as the National Institute for Health Research, with a 1.66-fold difference. Mean grant funding from public funding organisations was significantly greater for men at $£ 595361$ (SD $£ 1080718$ ) than for women at $£ 448414$ (SD £814 979). Differences were also statistically significant $(p>0.01)$ for UK MRC grants with men at $£ 751413$ (SD £1 020 748) and women at $£ 544427$ (SD £884 442) and for UK Government grants with men at £208 828 (SD £492 519) and women at $£ 182907$ (SD $£ 619889$ ).

Median grant funding from public funding organisations had a similar pattern with significantly greater grant funding for men at £272 452 (IQR £138 322-£572 529) and women at £213 718 (IQR £92 880-£402 917). Differences were also statistically significant $(p>0.05)$ for UK MRC grants with men at $£ 404615$ (IQR £ 210068 $£ 811860$ ) and women at 2286679 (£178 182 to $£ 468998$ ), and for UK Government grants with men at 1129660 (IQR £23 761-£207 320) and women at £59976 (IQR $£ 12$ 564-£157 053).

Philanthropic funding organisations invested a total of $£ 691.7$ million in research led by men $(78.8 \%)$ and $£ 185.9$ million in research led by women $(21.2 \%)$. 
Figure 3 (A) Proportion of investment over time awarded to male and female principal investigators. (B) Total investment by research pipeline awarded to male and female principal investigators.

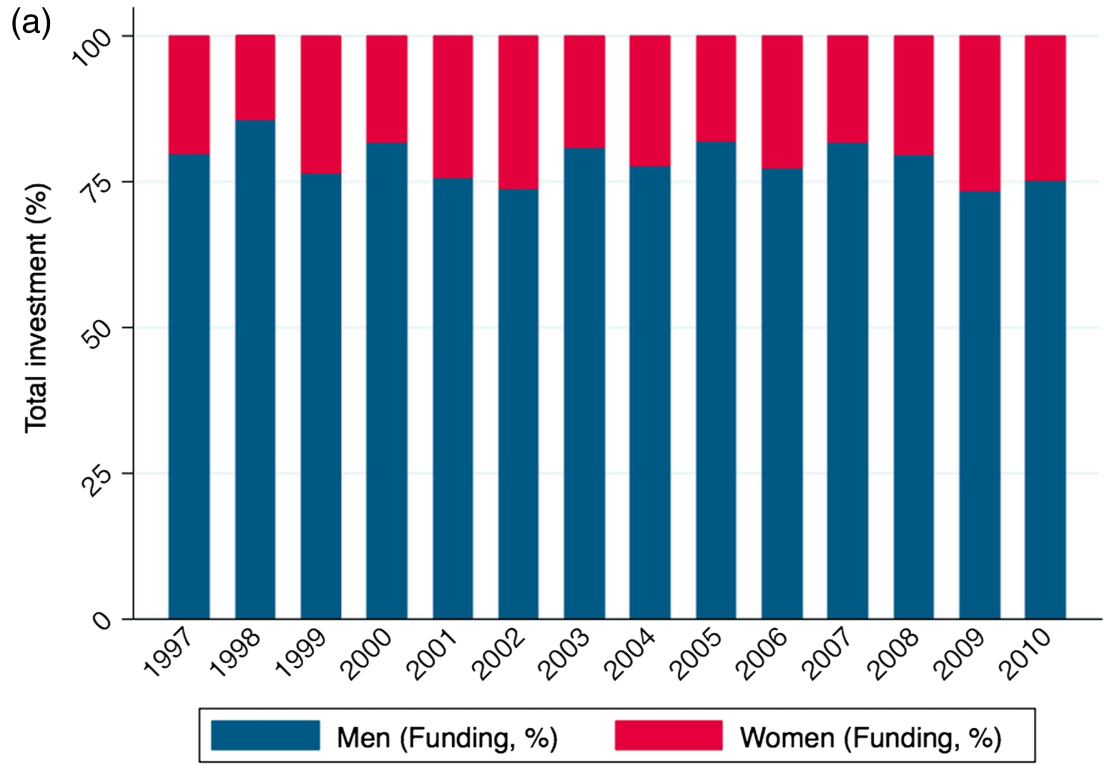

(b)

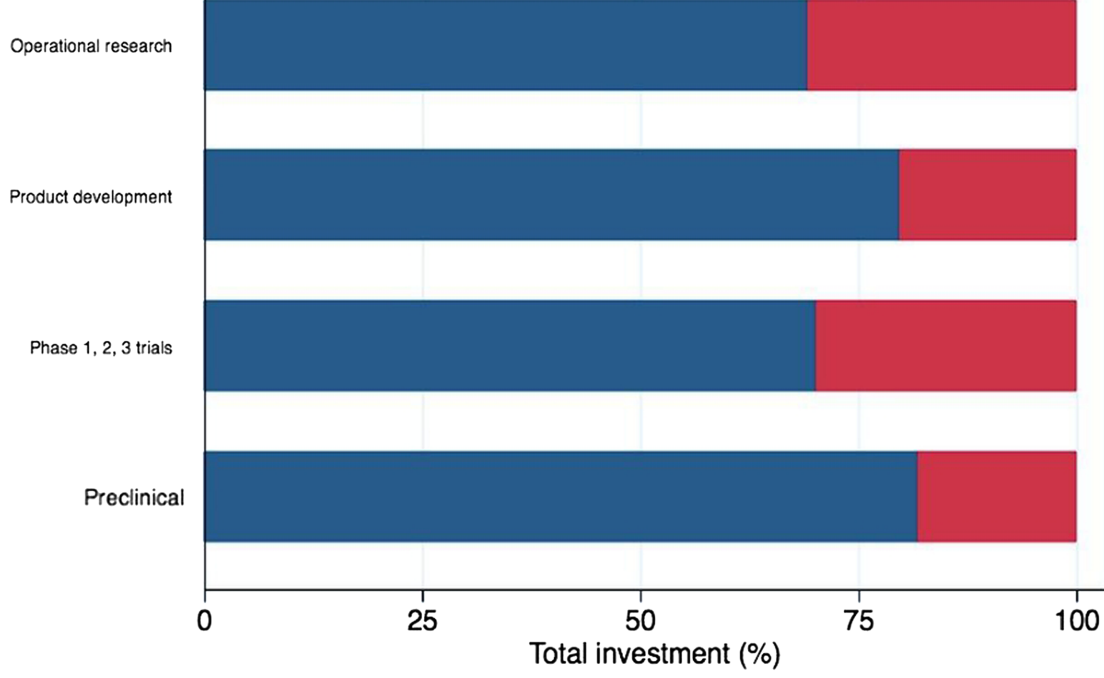

\begin{tabular}{|ll}
\hline Men (total funding, \%) Women (total funding, \%) \\
\hline
\end{tabular}

organisations with men receiving £91 991 (IQR £36 429$£ 172497$ ) and women $£ 76058$ (IQR £17 279-£150 727).

Figure 4 shows the association between funding organisation and total investment and median funding by gender. The MRC awarded the highest median amount in grants to women (£286 679; IQR £178 182-£468 998), but the median funding amount in grants for men were 1.41-fold higher than that awarded to women (£404 615; IQR £210 068-£811 860). The European Commission awarded the highest mean grants to women at $£ 923364$ (SD £1 316016 ); however, mean funding amount in grants for men was 1.44-fold higher at £1 325149 (SD $£ 2409860$ ) than that for women.

\section{Time trend}

Table 3 (see web appendix 3) shows in detail the trends in funding over time from 1997 to 2010 by gender of 
Figure 4 (A) Association between funding organisation and total investment by gender.

(B) Association between funding organisation and median award by gender. BBSRC,

Biotechnology and Biological Sciences Research Council; $\mathrm{DH}$, UK department of health; MRC, Medical Research Council.

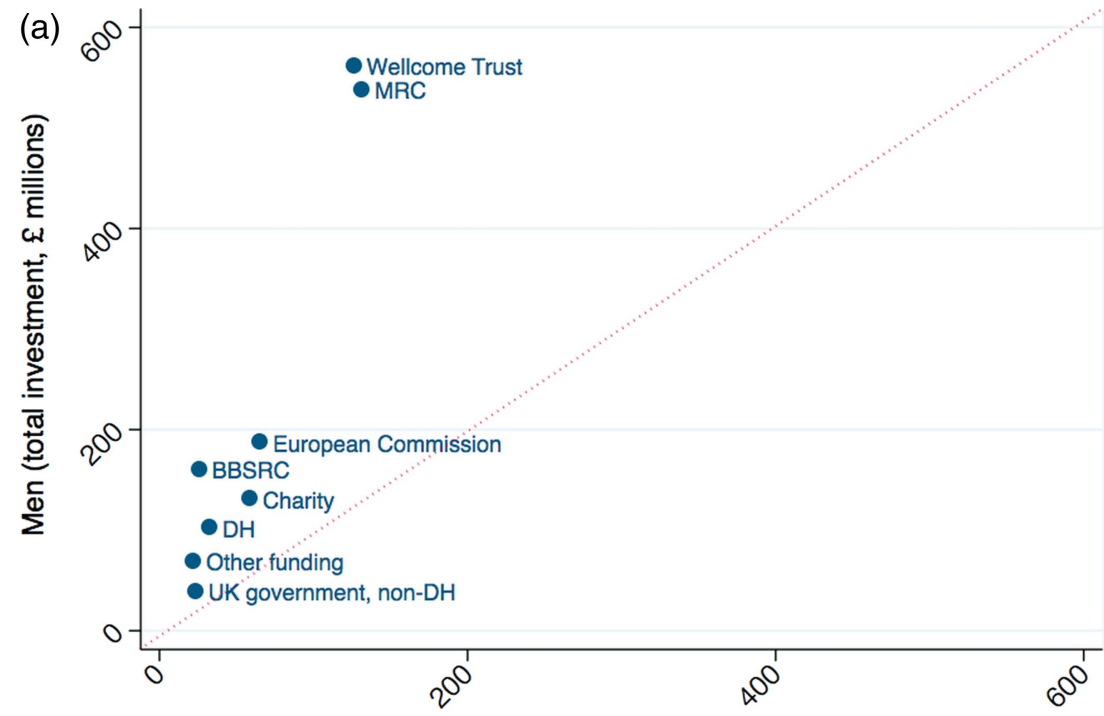

Women (total investment, $£$ millions)

(b)

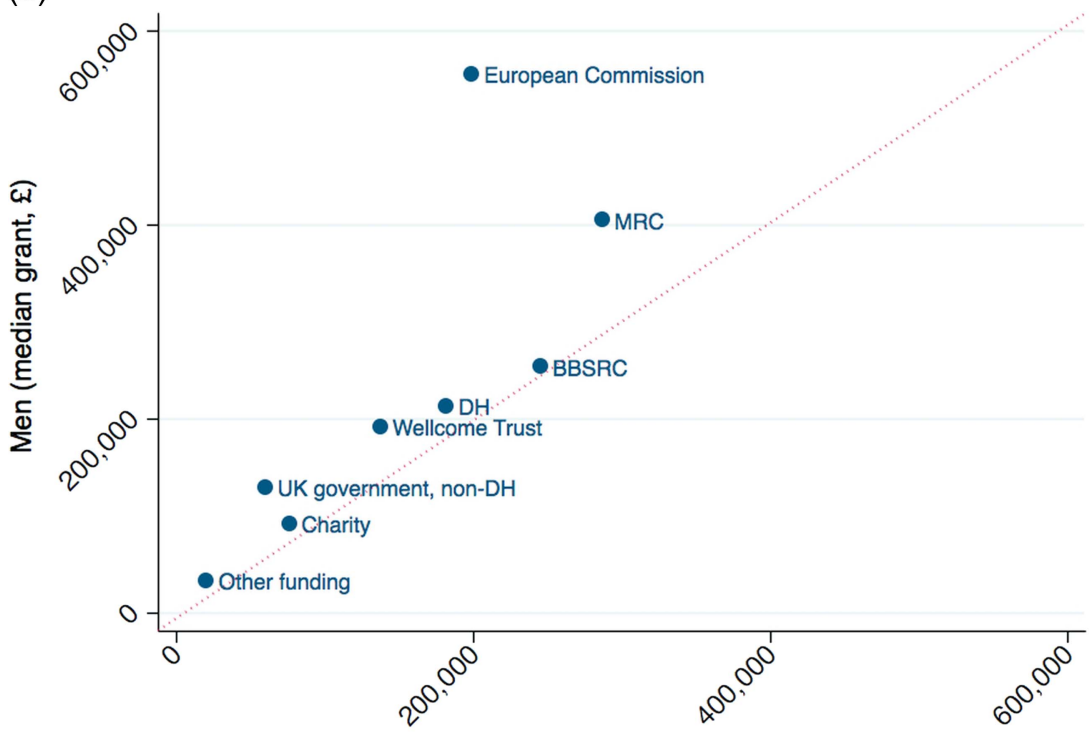

Women (median grant, £)
PIs, with amounts and relative proportions each year of funding. Mean annual funding received was greater by men at $£ 127.6$ million (SD $£ 48.7$ million) than women at $£ 34.9$ million (SD $£ 13.4$ million). Proportions of annual funding received by men ranged from $73.2 \%$ to $85.7 \%$, with a mean of $78.6 \%$.

Proportions of annual funding received by women ranged from $14.3 \%$ to $26.8 \%$ with a mean of $21.4 \%$. The largest annual funding received by men was $£ 245.7$ million in 2000 , and the smallest at $£ 64.2$ million in 1997. The largest annual funding received by women was $£ 59.6$ million in 2002 , with the smallest at $£ 13.1$ million in 1998.

Over the 14-year study period, the proportion of investment awarded to women each year remains relatively unchanged with a mean of $21.4 \%$ of total (range 14.3-26.8\%; £13.1 million to £59.6 million). Figure 5 shows the funding trends over time and fold differences in total investments by gender. The absolute difference in the funding amounts in the grants awarded to men and women ranges between $£ 47.9$ million and $£ 190.1$ million, with a mean difference of $£ 92.7$ million (SD $£ 38.3$ million). The fold difference in grant funding for men and women ranged from 2.74 to 5.97 , with a mean fold difference of 3.66 .

\section{DISCUSSION}

We present the first detailed and systematic comparison by sex of investments in infectious disease research in the UK for the 14-year period 1997-2010. We identified 6165 studies funded by public and philanthropic funding organisations, with a total research investment of $£ 2.6$ billion. 
Figure 5 (A) Total investment and trend over time, by gender. (B) Fold difference of investment over time, by gender. (a)

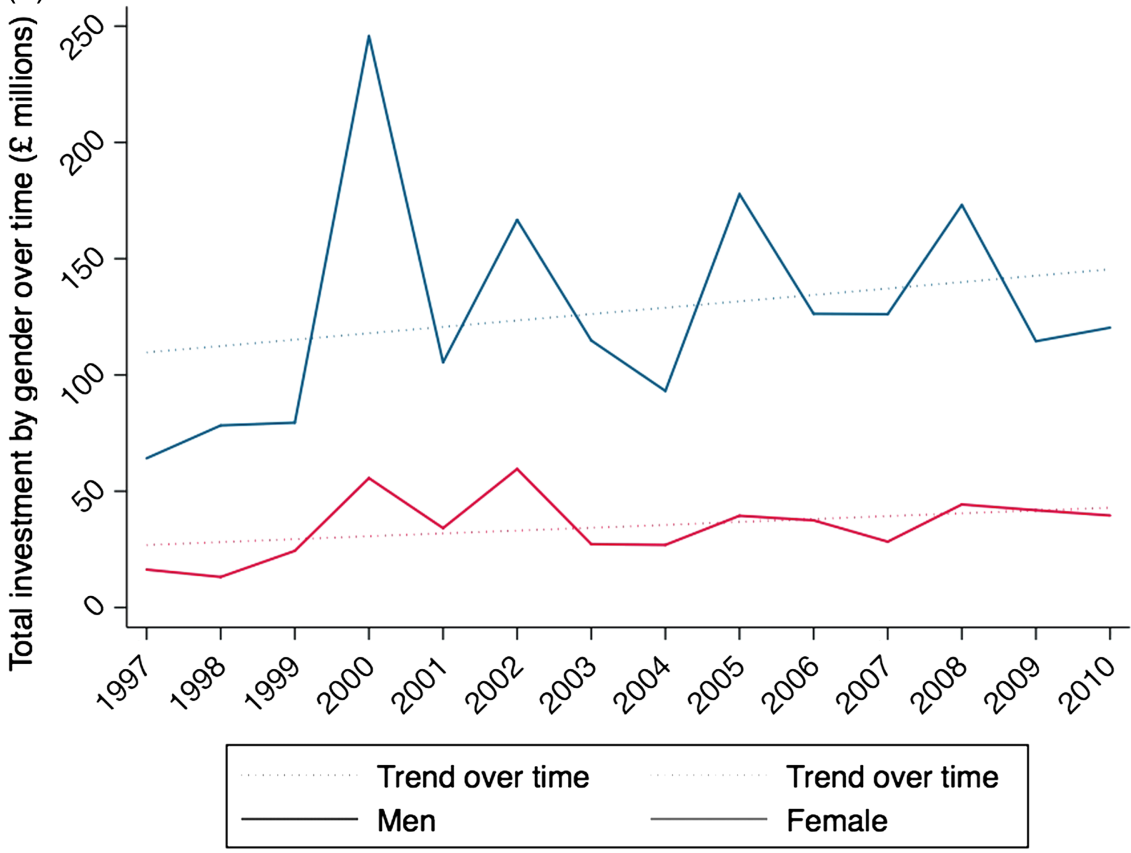

(b)

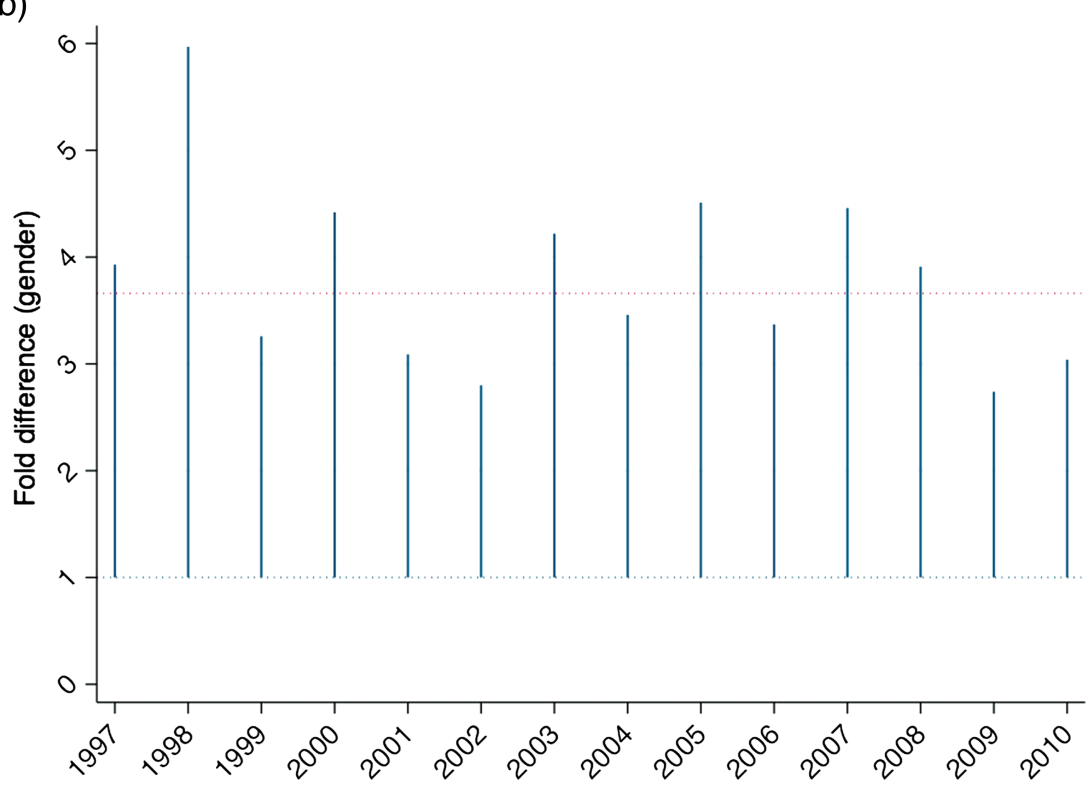

We quantified the differences in research funding awarded by gender to show these to be substantial. The analysis shows clear and consistent differences between men and women PIs, with lower funding in terms of the total investment, the number of funded studies, the median funding awarded and the mean funding awarded across most of the infectious disease areas funded. Women received less funding in absolute amounts and in relative terms, by funder and the type of science funded along the R\&D pipeline. These differences in funding between men and women persist over time.

We show large differences in median funding amounts for men and women researchers in investments by the
European Commission and the MRC. Such differences were much less apparent when comparing funding from the Department of Health and BBSRC, although the BBSRC awarded $86 \%$ of funding to men. The BBSRC almost entirely funds preclinical research, ${ }^{14}$ and this matches the increased proportions of preclinical studies being led by male PIs.

Our findings in infectious disease research, the most detailed until now, provide new evidence on differences between men and women researchers to reinforce the concerns raised in earlier studies. ${ }^{415}{ }^{16}$ Differences that are more marked at senior levels of academia need to be investigated to explain and account for the observed differences. 
The reasons why the median awards across most infectious disease conditions should be significantly less for women PIs cannot be deduced from the available data. Thus, it is not possible to recommend interventions to address this phenomenon, given that it is unclear if there is any bias or precisely what mechanisms are at play. The next step may be to investigate success rates by gender to assess how many women are applying and what proportion of the initial request for funding is actually allocated.

There have been suggestions that women are systematically less ambitious in the amounts of funding requested in their grant applications when compared with men who are equivalently ranked academically, and that relatively simple mentoring programmes could at least partially overcome this anomaly. ${ }^{3}$ However, there is no evidence supporting these assertions. Others have suggested that systems which ensure PI anonymity during review of grant funding submissions may help reduce the presence of any subtle gender biases, ${ }^{17}$ though in practice this approach would be challenging as the experience of PI is a key factor when considering the suitability of request for research support. However, evidence on effective interventions to address barriers for women scientists is lacking. ${ }^{16}$ Women of childbearing age are being disadvantaged in some areas of employment, even though in relation to scientific endeavour, productivity as measured by published outputs is not significantly different between women with and without children. ${ }^{15}$

\section{Study limitations}

Our analysis has several limitations. We rely on the accuracy of the original data from the funding organisations and, as described elsewhere, we have excluded data from the private sector as the publicly available data are incomplete. $^{14}$

In the period analysed, we were not able to find data on the number of men and women PIs requesting financial support for research agencies from the funding sources studies. Hence, we were unable to assess the success and failure rates by gender. We also did not have complete data on the amount of funding initially requested, the gender of coapplicants for each study, the total pool of researchers in each disease area and within each type of science, or the proportion of awards made to clinical and non-clinical researchers, all of which would be useful pieces of information in developing a clearer picture of the reasons for the presented differences. The proportion of doctors registered in the UK favours men $(56.8 \%$ as of January 2013) over women, ${ }^{18}$ but the proportion of those carrying out research appears to be unknown. Understanding the distribution of researchers is critical to an understanding of the research landscape.

We lacked data on the academic ranking of PIs and were hence unable to adjust for levels of seniority across both genders. We were unable to get data on gender from the Gates Foundation and DFID and hence were unable to clarify the gender of a small proportion of investigators, though we believe this limitation is not likely to change the conclusions of the study. Our analysis focuses on infectious disease research, and analysis of other areas of scientific research would be needed if these differences persisted for all research areas.

\section{CONCLUSIONS}

Notwithstanding the limitations, our systematic analysis shows an unequal distribution of investments in infectious disease research for men and women. There are fewer women receiving funding as PIs in infectious disease research, with fewer studies funded with lower funding amounts when successful.

Although earlier studies have discussed possible solutions, including mentoring programmes and advertising campaigns, none have systematically explored the reasons why such differences persist. Hence, without an understanding of the reasons for the observed differences, the proposed solutions are not very meaningful. There is no evidence that women and men researchers are not equally capable; hence, other factors are likely to be at play to explain the observed differences which have persisted over the 14-year study period. From our data, the limitations mean that we cannot explain what these mechanisms might be. Research is needed to elucidate an understanding of the factors that can explain the observed differences. A subanalysis of our dataset where information on academic rank at the time of award is obtained would allow for more meaningful conclusions. We strongly urge policy-makers, funders and scientists to urgently investigate the factors leading to the observed differences and develop policies developed to address them, in order to ensure that women are appropriately supported in scientific endeavour.

\section{Author affiliations}

${ }^{1}$ Research Department of Infection and Population Health, University College London, UCL Royal Free Campus, London, UK

${ }^{2}$ London School of Hygiene \& Tropical Medicine, London, UK

${ }^{3}$ Imperial College London, South Kensington Campus, London, UK

${ }^{4}$ Harvard School of Public Health, Harvard University, Boston, Massachusetts, USA

Acknowledgements The authors would like to thank Jennifer Harris and Raidah Haider for their input and assistance, and acknowledge the assistance of the research and development funding agencies for provision of data.

Contributors MGH designed the study with input from RA and JF and collated the dataset. JRF, FW and MKC checked and refined the dataset. JRF undertook data analysis and created the graphs and figures with input from MGH and RA. MGH, JRF and RA interpreted the data and wrote the first draft. MGH, JRF and RA refined the analysis and article with input from MKC and FBW. All authors reviewed and approved the final version. $\mathrm{MH}$ is the guarantor of the article.

Funding This research received no specific grant from any funding agency in the public, commercial or not-for-profit sectors.

Competing interests RA has received research funding from the UK Medical Research Council, the UK National Institute for Health Research, UK CRC, UK EPSCRC, the UK Department for International Development and the UK Department of Health. RA is a member of the UL Medical Research Council Global Health Group. MGH works for the Infectious Disease Research Network, which has supported this work and is funded by the UK Department of Health. 
JRF has received funds from the Wellcome Trust and is a steering group member for the Infectious Disease Research Network. MKC has received funding from the Medical Research Council and the Bill and Melinda Gates Foundation. FBW has received funds from the UCLH Charitable Foundation.

Provenance and peer review Not commissioned; externally peer reviewed.

Data sharing statement All gender data are available with this submission. Further data relating to the Research Investments project can be found at http://www.researchinvestments.org or by contacting MGH.

Open Access This is an Open Access article distributed in accordance with the Creative Commons Attribution Non Commercial (CC BY-NC 3.0) license, which permits others to distribute, remix, adapt, build upon this work noncommercially, and license their derivative works on different terms, provided the original work is properly cited and the use is non-commercial. See: http:// creativecommons.org/licenses/by-nc/3.0/

\section{REFERENCES}

1. Directorate-General for Employment, Social Affairs and Equal Opportunities Unit G1. More women in senior positions. Key to economic stability and growth. Luxembourg: European Commission, 2010. http://www.eubusiness.com/topics/employment/womensenior.10/

2. Blake M, La Valle I. Who applies for research funding? Key factors shaping funding application behaviour among women and men in British higher education institutions. London: Wellcome Trust, 2000.

3. Bedi G, Van Dam NT, Munafo M. Gender inequality in awarded research grants. Lancet 2012;380:474.

4. Fitzpatrick S. A Survey of Staffing Levels of Medical Clinical Academics in UK Medical Schools as at 31 July 2011. London, 2012. http://www. medschools.ac.uk/Publications/Documents/MSC_Clinical_Academic Staff_Survey_310711.pdf (accessed 22 Aug 2013).

5. Burrelli J. Thirty-Three Years of Women in S\&E Faculty PositionsUS National Science Foundation. Arlington, 2008. http://www.nsf. gov/statistics/infbrief/nsf08308/ (accessed 22 Aug 2013).
6. Lincoln AE, Pincus SH, Leboy PS. Scholars' awards go mainly to men. Nature 2011;469:472.

7. Pohlhaus JR, Jiang H, Sutton J. Sex differences in career development awardees' subsequent grant attainment. Ann Intern Med 2010;152:616-17; author reply 617.

8. Medical Research Council. MRC Gender Equality Scheme. 2007. http://www.mrc.ac.uk/Utilities/Documentrecord/index.htm? d=MRC003655 (accessed 22 Aug 2013).

9. European Commission. About this site-Science: It's a girl thing! 2012 http://science-girl-thing.eu/en/about-this-site (accessed 22 Aug 2013).

10. Gill M. "Science, it's a girl thing!" says EU Commission, holding lipstick and bunsen burner. New Statesman, 2012. http://www. newstatesman.com/blogs/martha-gill/2012/06/science-its-girl-thingsays-eu-commission-holding-lipstick-and-bunsen-burn (accessed 22 Aug 2013)

11. Swain F. Science: It's a girl thing. Excuse me while I die inside.SciencePunk. ScienceBlogs, 2012. http://scienceblogs.com/ sciencepunk/2012/06/22/science-its-a-girl-thing-excuse-me-while-idie-inside/ (date accessed 22 Aug 2013).

12. Yong E. Edit-a-thon gets women scientists into Wikipedia. Nature, 2012. http://www.nature.com/news/edit-a-thon-gets-womenscientists-into-wikipedia-1.11636 (accessed 22 Aug 2013).

13. Donald A. Throw off the cloak of invisibility. Nature 2012;490:447. http://www.nature.com/news/throw-off-the-cloak-of-invisibility-1. 11638 (accessed 22 Aug 2013).

14. Head MG, Fitchett JR, Cooke MK, et al. UK investments in global infectious disease research 1997-2010: a case study. Lancet Infect Dis 2013;13:55-64.

15. Fox MF. Gender, family characteristics, and publication productivity among scientists. Soc Stud Sci 2005;35:131-50.

16. Ceci SJ, Williams WM. Understanding current causes of women's underrepresentation in science. Proc Natl Acad Sci USA 2011:108:3157-62.

17. Moss-Racusin CA, Dovidio JF, Brescoll VL, et al. Science faculty's subtle gender biases favor male students. Proc Natl Acad Sci USA 2012;109:16474-9.

18. General Medical Council. List of Registered Medical Practitionersstatistics. http://www.gmc-uk.org/doctors/register/search stats.asp (accessed 22 Aug 2013). 